\title{
Meridional Overturning Circulation in a Multibasin Model. Part II: Sensitivity to Diffusivity and Wind in Warm and Cool Climates $\mathscr{}$
}

\author{
JonAthan A. BAKer, ${ }^{\mathrm{a}}$ ANDREW J. WATSOn, ${ }^{\mathrm{a}}$ AND GeOFFREy K. VAllis ${ }^{\mathrm{a}}$ \\ ${ }^{\mathrm{a}}$ University of Exeter, Exeter, United Kingdom
}

(Manuscript received 3 June 2020, in final form 10 March 2021)

\begin{abstract}
The response of the meridional overturning circulation (MOC) to changes in Southern Ocean (SO) zonal wind forcing and Pacific Ocean basin vertical diffusivity is investigated under varying buoyancy forcings, corresponding to "warm," "present day," and "cold" states, in a two-basin general circulation model connected by a southern circumpolar channel. We find that the Atlantic MOC (AMOC) strengthens with increased SO wind stress or diffusivity in the model Pacific, under all buoyancy forcings. The sensitivity of the AMOC to wind stress increases as the buoyancy forcing is varied from a warm to a present-day or cold state, whereas it is most sensitive to the Pacific diffusivity in a present-day or warm state. Similarly, the AMOC is more sensitive to buoyancy forcing over the Southern Ocean under reduced wind stress or enhanced Pacific diffusivity. These results arise because of the increased importance of the Pacific pathway in the warmer climates, giving an increased linkage between the basins and so the opportunity for the diffusivity in the Pacific to affect the overturning in the Atlantic. In cooler states, such as in glacial climates, the two basins are largely decoupled and the wind strength over the SO is the primary determinant of the AMOC strength. Both wind- and diffusively driven upwelling sustain the AMOC in the warmer (present day) state. Changes in SO wind stress alone do not shoal the AMOC to resemble that observed at the last glacial maximum; changes in the buoyancy forcing are also needed to decouple the two basins.
\end{abstract}

KEYWORDS: Ocean; Diffusion; Meridional overturning circulation; Ocean circulation; Wind stress; Ocean models

\section{Introduction}

The global meridional overturning circulation (MOC) plays a vital role in the transport and air-sea exchange of both heat and carbon, and consequently in modulating global climate. Dense waters in the present-day North Atlantic Ocean sink to form North Atlantic Deep Water (NADW) and must be balanced by upwelling elsewhere. This upwelling was originally believed to occur diffusively throughout the ocean via interior vertical mixing (e.g., Munk 1966), but observational estimates of the diffusivity of order $10^{-5} \mathrm{~m}^{2} \mathrm{~s}^{-1}$ are an order of magnitude too small to sustain the present-day NADW cell (Gregg 1989; Ledwell et al. 1993; Toole et al. 1994; Wang and Huang 2005), leading to the so-called "missing mixing" problem.

An alternative mechanism to drive an interhemispheric MOC, via wind-driven adiabatic upwelling in the Southern Ocean (SO), was proposed by Toggweiler and Samuels (1995, 1998) and Doos and Coward (1997), showing that a substantial MOC could persist even with little diapycnal mixing, and these effects were further explored by Vallis (2000), Wolfe and Cessi (2010), and others. Conceptual models and theories of these processes were put forward by Gnanadesikan (1999), Samelson (2004), and Nikurashin and Vallis (2011, 2012), and reviews and a general theoretical discussion can be found in Kuhlbrodt et al. (2007), Vallis (2017), and Cessi (2019).

Supplemental information related to this paper is available at the Journals Online website: https://doi.org/10.1175/JPO-D-200121.s1.

Corresponding author: Jonathan Baker, jb812@exeter.ac.uk
Renewed attention to diffusive processes came about through simulations with multibasin configurations (Jochum and Eden 2015; Jones and Cessi 2016; Ferrari et al. 2017; Newsom and Thompson 2018; Baker et al. 2020, hereinafter Part I; Nadeau and Jansen 2020). These studies show that diffusive upwelling in the Pacific Ocean can, at least in part, drive an Atlantic meridional overturning circulation (AMOC). ${ }^{1}$ An enhanced diapycnal diffusivity increases the overlap between the upper and lower overturning cells, increasing the connection between the basins and strengthening the AMOC (Nadeau and Jansen 2020). These studies are largely consistent with observations that suggest a significant volume of NADW that upwells in the SO is converted to AABW before flowing into the IndoPacific (Lumpkin and Speer 2007; Talley 2013). Both diffusive and wind-driven processes are generally believed to play a role in the present-day overturning circulation, although the relative importance of these mechanisms is still not precisely known. Wind effects are moderated by the fact that that changes in the wind-induced circulation in the SO are in part compensated by opposing changes in the eddy-induced circulation (e.g., Farneti et al. 2010), but nevertheless they remain significant in eddy-resolving simulations (Wolfe and Cessi 2010; Bishop et al. 2016).

Given that the wind itself is important to the ocean structure, changes in SO wind may have significant effects on climate. For example, a weakening or equatorward shift in the SO westerly winds has been suggested as a mechanism to cause the drawdown

\footnotetext{
${ }^{1}$ We use the "AMOC" as a slight generalization of the "NADW cell," applying when the cell is either deep or shallow.
} 
of atmospheric $\mathrm{CO}_{2}$ (Toggweiler et al. 2006; Lauderdale et al. 2013) via the transition of the MOC to one with a weaker, shallower NADW cell (Lynch-Stieglitz et al. 1999; Curry and Oppo 2005). Paleo-proxy data and models are unfortunately insufficiently precise to accurately determine the changes in SO winds at the Last Glacial Maximum (LGM) but a weakening of the SO winds during glacial times is very possible (Rojas et al. 2009; Kohfeld et al. 2013). Compounding the difficulty, the response of the AMOC to past and future climate forcings differs substantially in state-of-the-art global climate models. For example, simulations of glacial climates in the Paleoclimate Modeling Intercomparison Project (PMIP) show a large range of changes in the AMOC depth and strength (e.g., Otto-Bliesner et al. 2007; Muglia and Schmittner 2015), and although models generally predict a transient weakening of the AMOC in a future warmer climate, the magnitude of change varies greatly (e.g., Weijer et al. 2020).

The overall goal of this study (taken with its predecessor, Part I), is to better understand how the various "forcings" of the ocean, specifically the wind, diffusivity, and surface buoyancy forcing, affect the overturning circulation in a multibasin ocean, and how that overturning circulation might change in a cold or a warmer climate. In Part I we focused on the basic effects of buoyancy forcing, showing how the AMOC shoals and weakens as the SO buoyancy forcing is varied from that corresponding to a warmer climate to that of a colder, more glacial climate (also see Watson and Naveria Garabato 2006; Ferrari et al. 2014; Jansen and Nadeau 2016; Nadeau et al. 2019; Sun et al. 2020). This shoaling reduces the connection of the AMOC with the lower cell in the SO and consequently the Pacific basin, effecting a separation between the circulation in the Atlantic and Pacific basins. In this paper we extend that study by evaluating the sensitivity of the AMOC to diffusivity and wind and how that sensitivity might vary depending on whether the climate is warm or cool. Specifically, we seek to answer following questions:

1) How does the sensitivity of the AMOC to SO wind stress and Pacific diffusivity vary with buoyancy forcing? Relatedly, how does the sensitivity to buoyancy forcing vary with SO wind stress and Pacific diffusivity?

2) Can reduced SO wind stress alone explain the shoaling and weakening of the AMOC in glacial times?

3) Can the wind- and diffusive-driven upwelling mechanisms that sustain the AMOC (among other factors) be separated?

This paper is organized as follows: in section 2, the ocean-sea ice model and experiments performed are described; in section 3, we describe our method and control simulations; in sections 4 and 5, we describe and compare the MOC changes in experiments in which we vary the SO wind forcing or Pacific vertical diffusivity; in section 6, we discuss the AMOC upwelling mechanisms; and in section 7 , we summarize and conclude.

\section{Model setup and experiments}

We use the Massachusetts Institute of Technology general circulation model (MITgcm) (Marshall et al. 1997a,b) with a $2.8^{\circ}$ horizontal resolution and 20 vertical levels in a 4000-m-deep ocean. An idealized domain is used (Fig. 1a) with two basins (referred to as "Atlantic" and "Pacific") connected by a reentrant circumpolar channel in the south. The basins have an area representative of the Atlantic and Pacific Oceans. The domain extends from $70^{\circ} \mathrm{S}$ to $73^{\circ} \mathrm{N}$ in the Atlantic basin and to $65^{\circ} \mathrm{N}$ in the Pacific basin. The model has a longitudinal extent of $188^{\circ}$, with an Atlantic basin of $63.5^{\circ}$ and a Pacific basin of $123.5^{\circ}$. There are two meridional land strips extending from the north of the model, which represent and are referred to herein as the South America and South Africa land strips, extending to a latitude of $53^{\circ}$ and $36^{\circ} \mathrm{S}$, respectively. The SO south of the South Africa land strip is herein referred to as the "channel."

The model is forced at the surface by a wind stress (Fig. 1b), and heat and freshwater fluxes. Sea ice is simulated using a fully coupled dynamic-thermodynamic sea ice model (Hibler 1979; Zhang and Hibler 1997; Losch et al. 2010), which accounts for the effects of sea ice on the buoyancy fluxes. The sea ice freezing point is perturbed as a convenient way to represent variations in $\mathrm{SO}$ sea ice formation and thus changes in the surface buoyancy flux. Sea ice freezing points set to $-1.96^{\circ} \mathrm{C}$, $0^{\circ}$, and $1^{\circ} \mathrm{C}$ simulate surface buoyancy conditions representative of a warm (W), a present-day (P), and a cold (C) state, respectively as shown in Part $\mathrm{I}$, where further reasoning for this approach is provided. The vertical ocean diffusivity is set using the Bryan and Lewis (1979) diffusion scheme (BL79) (Fig. 1c) and the Gent-McWilliams-Redi (GM-Redi) scheme is used to parameterize mesoscale eddies (Gent and McWilliams 1990; Gent et al. 1995; Redi 1982). Further model details are described in Part I.

Our experiments perturb either the SO zonal wind stress $\tau$ (south of $36^{\circ} \mathrm{S}$; Fig. 1b) or the background vertical diffusivity in the Pacific basin $\kappa$ (Figs. 1c,d) by factors ranging from 0 to 4 relative to the control experiments, these being the warm, present-day, and cold buoyancy state experiments described above. The model is spun up over several thousand years in each of the control states and is then integrated for a further 10000 years in the perturbation experiments to ensure a steady state is reached in all experiments.

We only vary the background vertical diffusivity in the Pacific basin so we can determine the sensitivity of the AMOC to changes in the interbasin transport, which varies significantly with buoyancy forcing (see section $3 b$ ). The model uses a second-order centered difference advection scheme so has little numerical mixing (Griffies et al. 2000), although numerical noise does occur. The parameterized mesoscale eddies cause negligible diffusive upwelling over most of the Pacific basin as the isopycnals are approximately horizontal (except at enhanced background diffusivity). Therefore, reducing the background vertical diffusivity in the Pacific basin is approximately equal to reducing the effective vertical diffusivity in this basin. At zero Pacific basin diffusivity, the large-scale Pacific overturning circulation is virtually nonexistent (see the middle panel of Figs. 3d, 4d, and 5d).

By varying the SO wind stress and Pacific diffusivity over a wide parameter space, we can explore MOC pathways and the AMOC response to these perturbations. The reduction to a zero SO wind stress and Pacific diffusivity allows us to infer the 


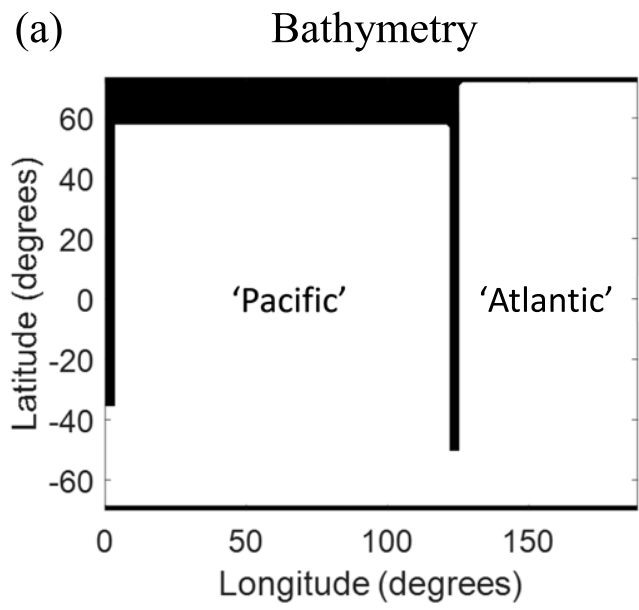

(c) Pacific vertical diffusivity

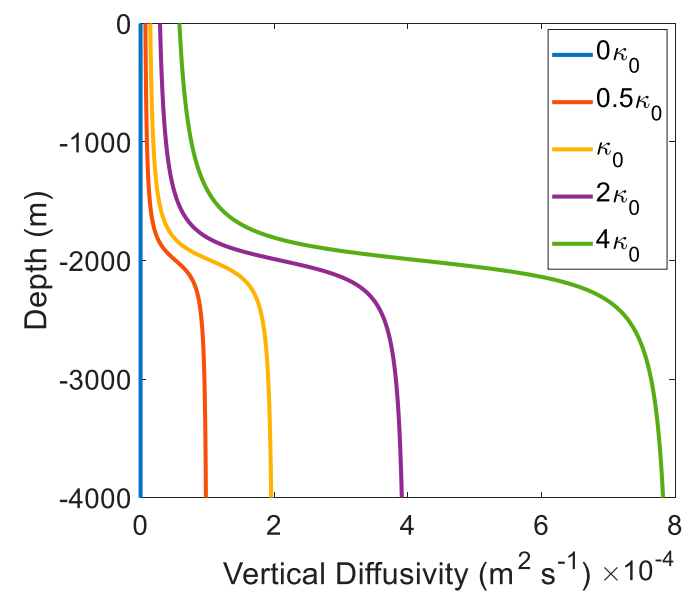

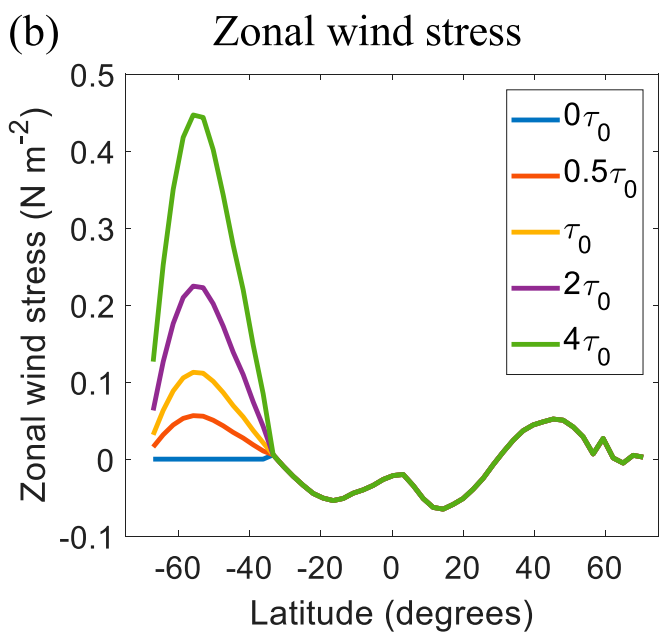

(d) Pacific vertical diffusivity $(\log )$

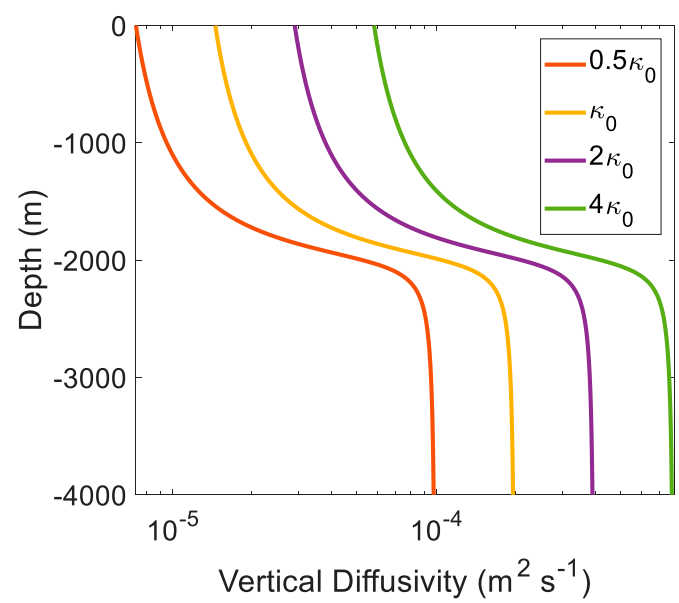

FIG. 1. (a) Bathymetry of the multibasin model. The ocean is shaded white, and land is shaded black. (b) Zonal wind stress forcing $\tau\left(\mathrm{N} \mathrm{m}^{-2}\right)$ and (c),(d) Pacific basin vertical diffusivity $\kappa\left(\mathrm{m}^{2} \mathrm{~s}^{-1}\right)$ in each of the model experiments: the control (labeled $\tau_{0}$ or $\kappa_{0}$ ) and the zero, half, twofold, and fourfold perturbation experiments. The zero diffusivity profile is not plotted in (d) since the $x$ axis is logarithmic.

role these parameters play in sustaining the AMOC, aiding our discussion of its driving mechanisms in section 6 .

\section{Methods and control simulations}

\section{a. Methods}

In contrast to a single-basin model (or the global-integrated circulation), the NADW cell in the Atlantic basin and the Pacific Deep Water (PDW) cell in the Pacific basin of a multibasin model can flow into the channel's global-integrated lower and upper cells, respectively (i.e., the upper and lower cells intersect) at the channel-basin boundary (Fig. 2).

A method to separate the MOC pathways by analyzing the overturning streamfunction was described in Part I and using this method each MOC component is labeled in Fig. 2 (along with the AMOC strength) and defined in Table 1. The depth of the interface between the global-integrated upper and lower cells at the channel-basin boundary is referred to as the "z_interface" (Fig. 2).
The overlap between the NADW cell in the Atlantic basin and the global-integrated lower cell in the channel, herein referred to as the "cell overlap," is critical in determining the pathways of NADW. It controls to a large extent the flow along the Pacific pathway, although we also account for any zonal pathway of NADW into the Pacific basin above the z_interface (see Table 1).

The PDW return pathway, PDW_At, returns water from the Pacific basin to the Atlantic basin via zonal flows, upwelling further via the channel's wind-driven upper cell in some cases. Therefore, the direct wind pathway, NADW_wind, is not always equal to the total adiabatic upwelling by the channel's wind-driven upper cell because the total adiabatic upwelling can also include upwelling of PDW. The direct wind pathway may thus increase to compensate for a decrease in the Pacific pathway, as occurs in the warm buoyancy state experiments. Similarly, the Pacific pathway will be shown to compensate for changes in the direct wind pathway in some cases due to structural changes in the MOC. We discuss this compensating 

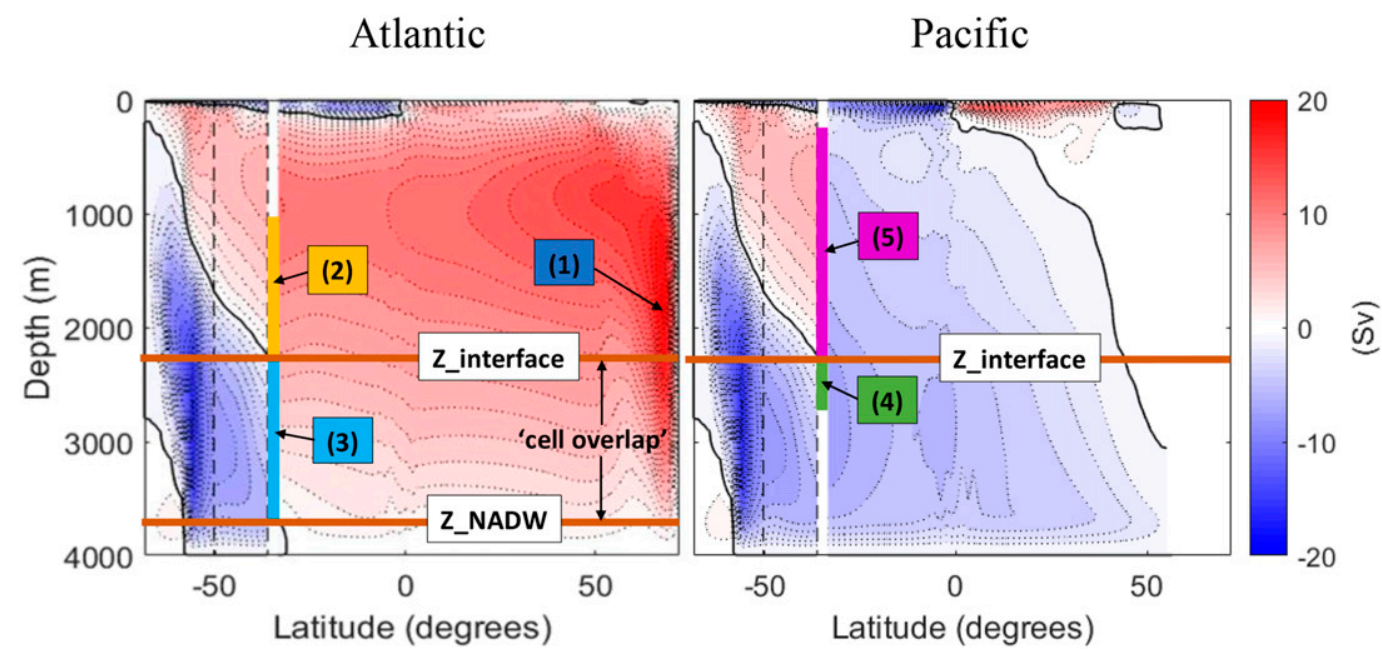

FIG. 2. Net zonal and depth-averaged meridional overturning streamfunction in the warm buoyancy state control, with the model (left) Atlantic and (right) Pacific, and the global-integrated streamfunction plotted in the channel. The strength of the AMOC is labeled as 1 . Overturning components, equal to the net southward flow into the channel over the depth of the corresponding vertical lines are direct wind pathway NADW_wind (label 2), Pacific pathway NADW_Pac (label 3), PDW isolated pathway PDW_sep (label 4), and PDW return pathway PDW_At (label 5). The Atlantic pathway, NADW_At is equal to the difference between 1 and the total pathway of NADW into the channel $(2+3)$. The $z_{-}$interface is the depth separating the global-integrated upper and lower overturning cells at the channelbasin boundary, and z_NADW is the depth of the NADW at the channel-basin boundary. The cell overlap is the overlap between the Atlantic upper cell and the global-integrated lower cell in the channel. Component 3 is strictly only the lower Pacific pathway, and if there is a pathway of NADW into the Pacific above z_interface, component 2 is reduced accordingly. The solid black contour is the 0 -Sv streamline, and vertical dashed lines are, from left to right, the southernmost latitudes of the South America and South Africa land strips, respectively. Note that we plot the streamfunction in depth space throughout this paper but we calculate the MOC components in isopycnal space.

behavior in section 6 . These pathways are representative of the net overturning flows (i.e., following the overturning streamlines) rather than that of an individual water parcel.

\section{b. MOC components in the control experiments}

The three control experiments, the warm (Fig. 3c), presentday (Fig. 4c), and cold (Fig. 5c) buoyancy states are each forced by the same control SO zonal wind stress, $\tau_{0}$, and Pacific vertical diffusivity, $\kappa_{0}$. The main difference between the MOC in these control experiments is the depth and strength of the
AMOC, as described in Part I. In the present-day buoyancy state control (Fig. 4c), the direct wind pathway, NADW_ wind, and the Pacific pathway, NADW_Pac, have similar magnitudes (see Figs. 6b,c, green stars), contributing to an $\sim 12$-Sverdrup ( $\mathrm{Sv} ; 1 \mathrm{~Sv} \equiv 10^{6} \mathrm{~m}^{2} \mathrm{~s}^{-1}$ ) AMOC. In the warm state the AMOC strengthens to about $17 \mathrm{~Sv}$ and deepens (Fig. 3c), with an increase in the Pacific pathway and a decrease in the direct wind pathway (Figs. 6b,c, red stars) as the cell overlap increases. In contrast, in the cold state enhanced negative SO buoyancy fluxes shoal and weaken the

TABLE 1. Definitions and abbreviations of the pathways of NADW and PDW in our multibasin model. The labeled numbers correspond to the components labeled in Fig. 2.

\begin{tabular}{|c|c|c|}
\hline MOC pathway & Abbreviation & Definition \\
\hline Direct wind pathway (component 2) & NADW_wind & $\begin{array}{l}\text { NADW pathway upwelled by the wind-driven upper cell as it flows into the } \\
\text { channel, before returning directly to the Atlantic basin nearer the surface } \\
\text { (i.e., no flow into the Pacific basin) }\end{array}$ \\
\hline Pacific pathway (component 3 ) & NADW_Pac & $\begin{array}{l}\text { NADW pathway that ultimately upwells in the Pacific basin, entering the } \\
\text { basin via zonal flows in the channel, either directly or via the channel's } \\
\text { lower anticlockwise cell }\end{array}$ \\
\hline Atlantic pathway & NADW_At & $\begin{array}{l}\text { NADW pathway that upwells in the Atlantic basin and returns northward } \\
\text { nearer the surface, without flowing into the channel }\end{array}$ \\
\hline PDW isolated pathway (component 4) & PDW_sep & $\begin{array}{l}\text { PDW pathway that upwells in the Pacific basin and flows into the channel's } \\
\text { lower cell; it is therefore isolated from the upper cell of the Atlantic basin }\end{array}$ \\
\hline PDW return pathway (component 5) & PDW_At & $\begin{array}{l}\text { PDW pathway that upwells in the Pacific basin and returns to the Atlantic } \\
\text { basin via zonal flows; further upwelling in the channel's upper cell occurs in } \\
\text { some cases, before returning to the Atlantic }\end{array}$ \\
\hline
\end{tabular}




\section{'Warm' state $\tau$ and $\kappa$ perturbation experiments}
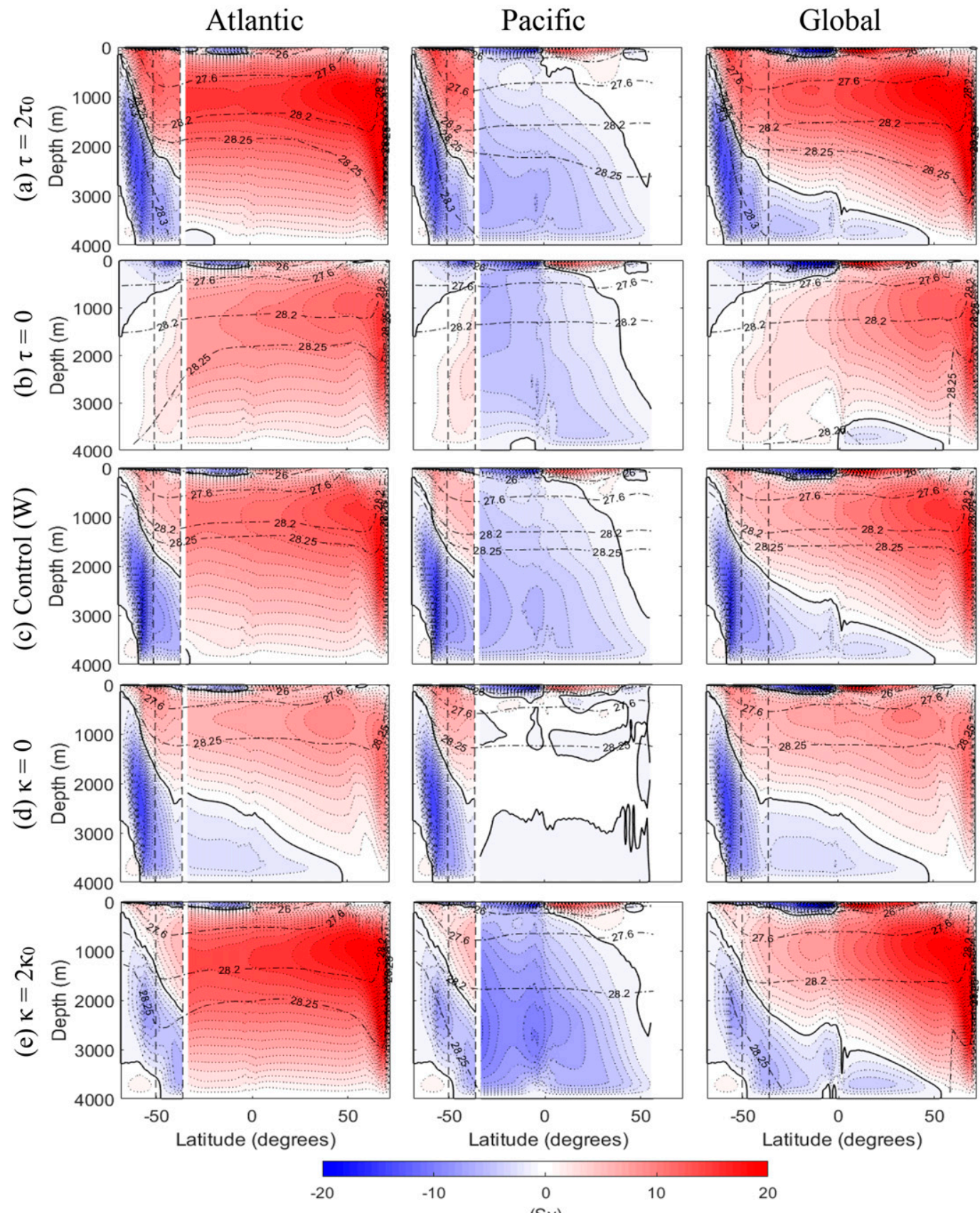

FIG. 3. Net overturning streamfunction (1-Sv contour intervals) in 'the warm' state for (a),(b) changes in SO zonal wind stress $\tau$ relative to the control, as labeled; (c) control; and (d),(e) changes in Pacific vertical diffusivity $\kappa$ relative to control, as labeled. Shown are the (left) Atlantic-, (center) Pacific-, and (right) global-integrated circulations, respectively, with the global-integrated streamfunction plotted in the channel in all plots. Potential density $\left(\mathrm{kg} \mathrm{m}^{-3}\right)$ contours are shown with thin dash-dotted black lines. 


\section{Present-day state $\tau$ and $\kappa$ perturbation experiments}

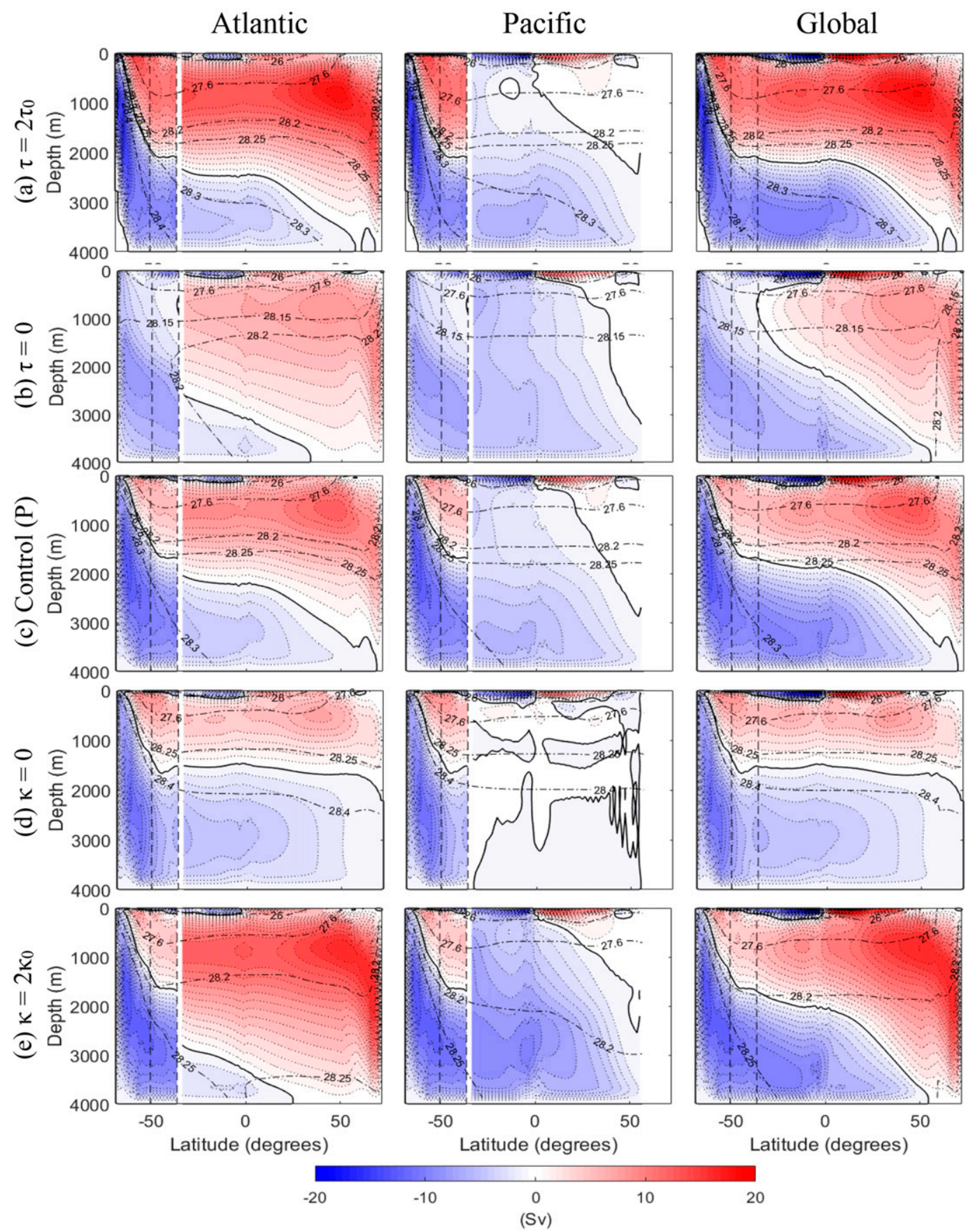

FIG. 4. As in Fig. 3, but for present-day state. 
'Cold' state $\tau$ and $\kappa$ perturbation experiments
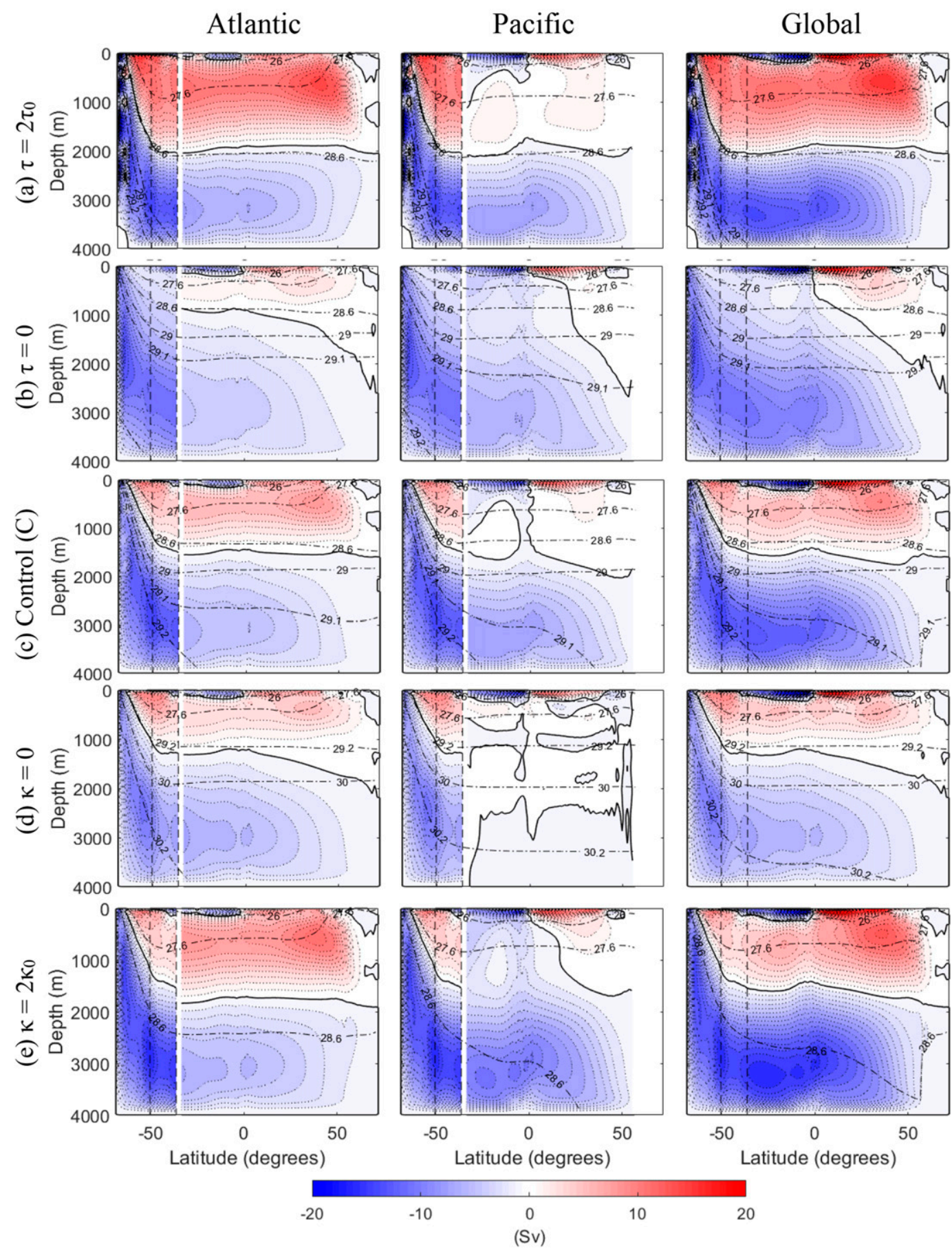

FIG. 5. As in Fig. 3, but for cold state. 

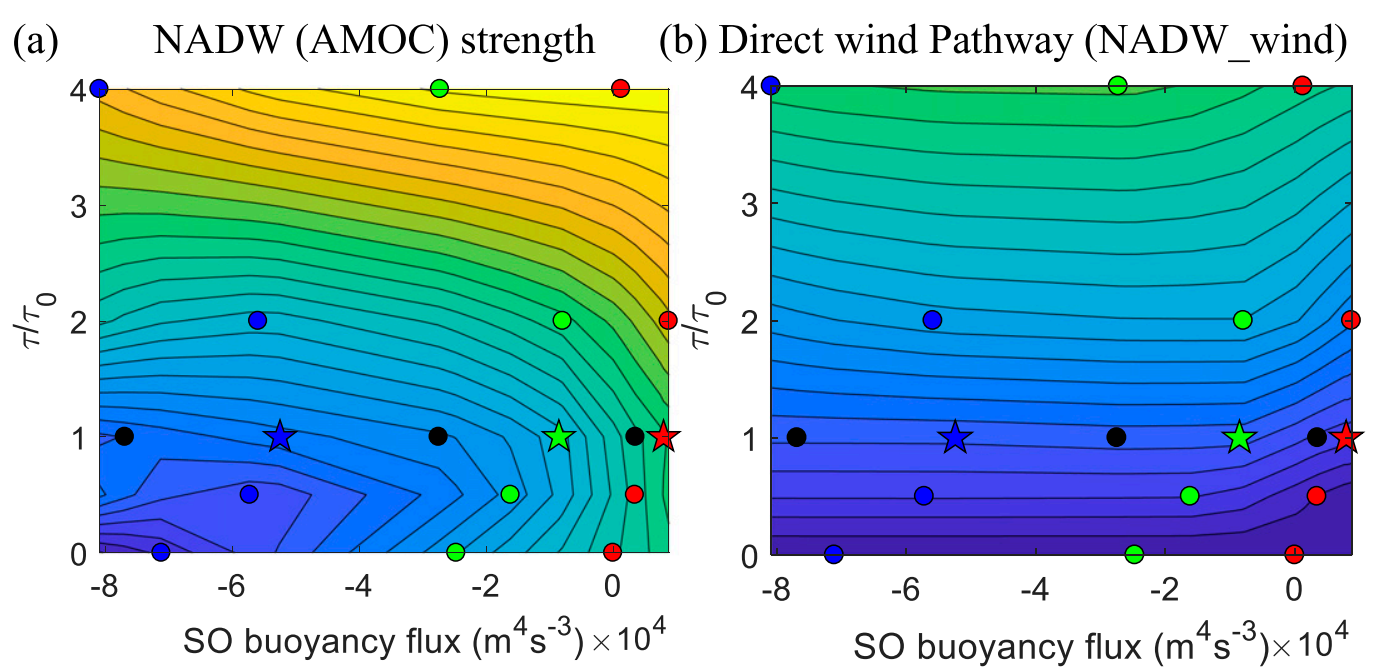

(c) Pacific Pathway (NADW_Pac)

(d) Atlantic Pathway (NADW_At)
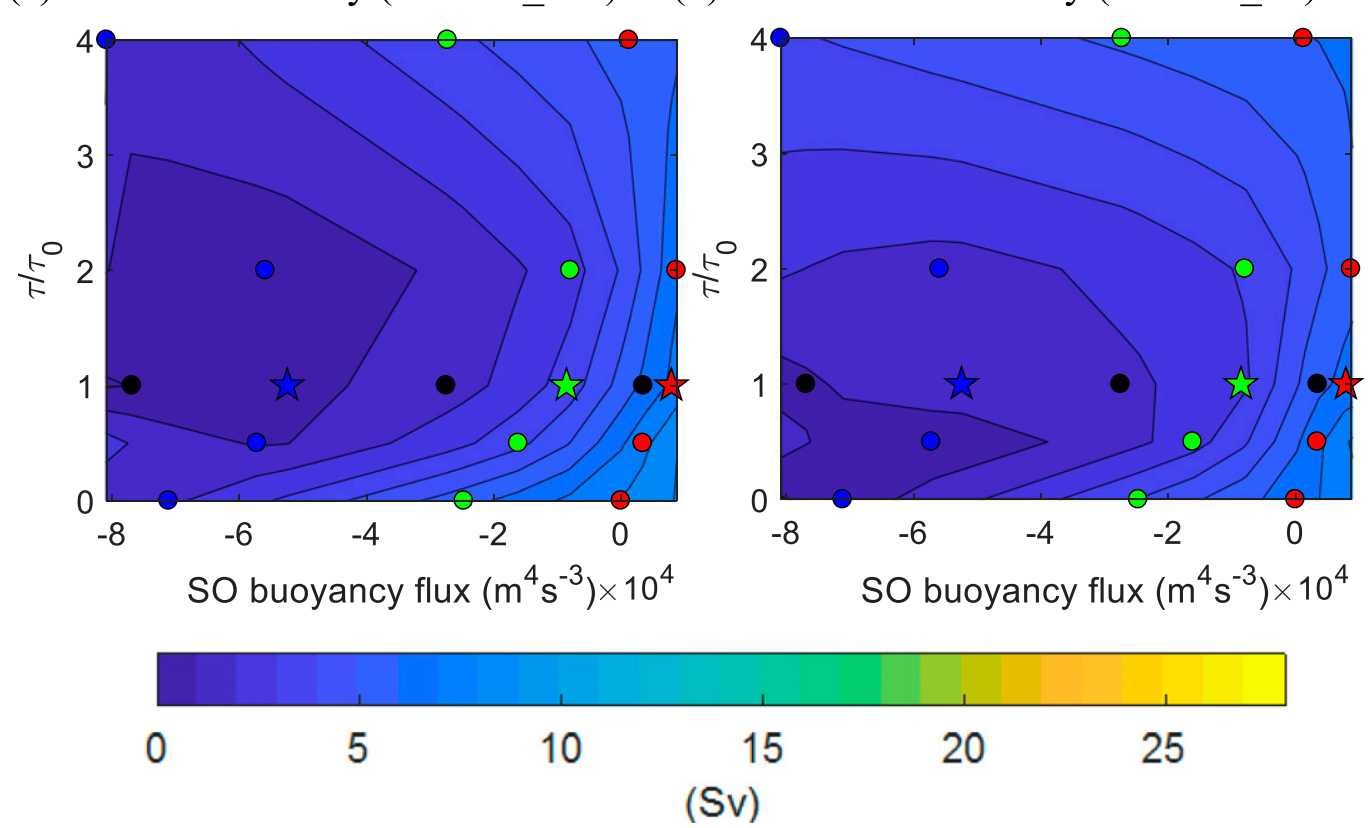

FIG. 6. Overturning transport components as a function of SO zonal wind stress $\tau$ relative to the control value $\tau_{0}$, and the area-integrated SO buoyancy flux. Components plotted are (a) NADW (AMOC) strength, (b) NADW_wind, (c) NADW_Pac, and (d) NADW_At. Symbols represent experiments performed including the warm (red), present day (green), and cold (blue) buoyancy state experiments, with the control experiments denoted by a star. The black dots represent additional SO buoyancy perturbation experiments performed in Part I. Contour intervals are $1 \mathrm{~Sv}$.

AMOC (Fig. 5c). The cell overlap is reduced, decoupling the upper and lower cells and isolating the AMOC from the Pacific basin. Thus, the AMOC is primarily wind-driven in the cold state (Fig. 6b, blue star).

The direct wind pathway tends to increase slightly while the Pacific pathway decreases greatly as the buoyancy forcing is varied from a warm to a cold state (Figs. 4b,c, red to blue stars, and Fig. 7c of Part I), as shown in Part I. Thus, we predict the sensitivity of the AMOC to changes in SO wind stress and Pacific diffusivity will increase and decrease, respectively, as the buoyancy forcing approaches a cold state.

\section{c. A note on the MOC coordinate system}

In this paper, the MOC components are calculated from the overturning streamfunction in isopycnal coordinates, although we show the circulations in depth coordinates. ${ }^{2}$ The overturning plots therefore do not correspond exactly to our MOC

\footnotetext{
${ }^{2}$ The depth coordinate shown is the same in each experiment, enabling more direct comparisons of the MOC in depth coordinates and variations in the cell overlap to be inferred.
} 
component calculations, although the key changes are the same in each coordinate system. The main difference is a reduction in the magnitude of Atlantic upwelling of NADW, NADW_At, and thus the AMOC strength in isopycnal coordinates, particularly in some of the high-wind and highdiffusivity perturbation experiments.

\section{Wind perturbation experiments}

We perturb the SO zonal wind stress from zero to a fourfold increase relative to the control (Fig. 1b), from each of the control buoyancy states: the warm, present-day, and cold states described in section $3 \mathrm{~b}$. We refer to each of the perturbation experiments as being in a warm, present-day or cold buoyancy state according to the buoyancy state of the control experiment they are perturbed from.

\section{a. SO buoyancy response}

The SO buoyancy flux in the model is dependent on the model heat and freshwater forcings, the wind forcing, the sea ice formation and melt rates, and the overturning circulation. Therefore, the area-integrated SO buoyancy flux (south of $67^{\circ} \mathrm{S}$ ) can vary as the SO wind stress is perturbed. This variation can be inferred for each buoyancy state from the colored symbols in Fig. 6. As the SO zonal wind stress is increased, the SO buoyancy flux remains positive (effectively, heat into the ocean) in the warm buoyancy state (red symbols). In contrast, it becomes significantly more negative in the present-day and cold states at high wind stress (green and blue symbols) as the SO sea ice export and formation rates increase. It is also reduced under weaker SO winds in all buoyancy states due to the sea ice thickness increasing. Nonetheless, the SO buoyancy flux remains distinct between each buoyancy state under all wind perturbations.

\section{b. Changes in the AMOC and overturning pathways}

Changes in SO wind stress significantly alter the strength of the AMOC under all buoyancy forcings (Fig. 6a), primarily due to changes in the direct wind pathway, NADW_wind, which has a similar variation in each buoyancy state (Fig. 6b). This pathway changes due to variations in the strength and depth of the channel's wind-driven upper cell, which is no longer generated at zero SO wind stress (Figs. 3b, 4b, and 5b). ${ }^{3}$

The AMOC (i.e., effectively the upper cell) dominates the Atlantic basin circulation under all wind stress perturbations in the warm buoyancy state (Figs. 3a-c). At zero SO wind stress, the Pacific pathway of NADW, NADW_Pac, is maintained via zonal flows driven by density differences between the basins (e.g., Jones and Cessi 2016; Thompson et al. 2016; Ferrari et al. 2017).

\footnotetext{
${ }^{3}$ The channel is dominated by a weak clockwise eddy-induced cell in the warm buoyancy state (Fig. 3b) because without the wind or sea ice buoyancy-induced negative tilting of the SO isopycnals, they are sloped positively. In isopycnal space, nearly all of the $\sim 3 \mathrm{~Sv}$ of upwelling by this cell also upwells in the Pacific basin before returning to the Atlantic basin.
}

Similarly, the AMOC weakens by only about $2 \mathrm{~Sv}$ at zero SO wind stress in the present-day state (Fig. $4 \mathrm{~b}$ and green symbol at bottom of Fig. 6a). This is because both the Pacific and the Atlantic pathways of NADW, NADW_Pac and NADW_At, respectively, increase (green symbols at bottom of Figs. 6c,d), due to an increase in the cell overlap and a slight deepening of the AMOC (Fig. S1 in the online supplemental material). The AMOC is therefore not shoaled to an overturning representative of the LGM.

In contrast, in the cold buoyancy state there is a significant weakening of the AMOC (Fig. $5 \mathrm{~b}$ and blue symbol at bottom of Fig. 6a) because there is only a small increase in the Pacific pathway (Fig. 6c) and the Atlantic pathway decreases (Fig. 6d) as the AMOC shoals.

At enhanced wind stress, the Pacific pathway decreases slightly in the warm buoyancy state (red symbols at top of Fig. 6c) due to a decrease in the cell overlap (Fig. 3a). In the present-day and cold buoyancy states, the AMOC deepens (Figs. 4a and 5a) increasing the Atlantic pathway (green and blue symbols at top of Fig. 6d).

The AMOC is therefore most sensitive to a reduction in wind stress in the cold buoyancy state, although the presentday buoyancy state is about as sensitive to an enhanced wind stress (Fig. 8a, blue and green lines, respectively). The higher sensitivities in these cooler buoyancy states are primarily explained by the greater variation in the strength of the Atlantic pathway of NADW, NADW_At (blue and green symbols in Fig. 6d). The Pacific pathway in the warm buoyancy state also varies with wind stress, reducing the magnitude of changes in AMOC strength (red symbols in Fig. 6c).

\section{c. Eddy compensation}

Although the absolute variation of the AMOC to changes in SO wind stress will vary with the choice of eddy parameterization (because of variations in SO eddy compensation-see Munday et al. 2013), the qualitative differences in sensitivity between buoyancy states in our experiments should remain valid. The direction of change in the structure of the SO overturning with SO wind stress will in any case be similar to that in our experiments because as the wind stress is reduced to zero, the wind-driven upper cell cannot be generated, whereas it will be strengthened at enhanced wind stress. That said, the sensitivity may be much reduced in models with more eddy compensation, and our experiments do investigate unrealistically large changes in wind stress. On the other hand, models with realistic geometry have a wider southern channel, which could increase the sensitivity to changes in SO winds.

\section{Effects of Pacific vertical diffusivity}

We now describe the results of experiments in which we change the vertical diffusivity in the Pacific basin by factors ranging from zero to four relative to the control (see Figs. 1c,d). ${ }^{4}$

\footnotetext{
${ }^{4}$ Our zero Pacific diffusivity experiments are analogous to the "long ACC" single-basin experiment of Nadeau and Jansen (2020).
} 
(a) NADW (AMOC) strength

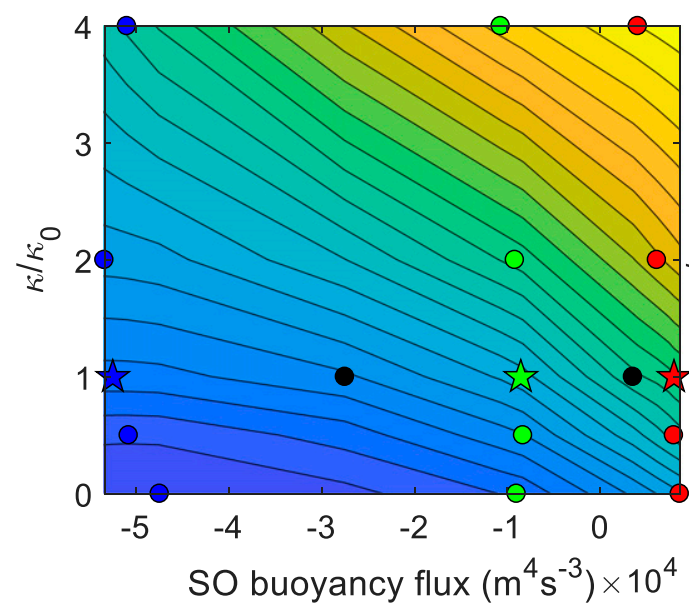

(c) Pacific Pathway (NADW_Pac)

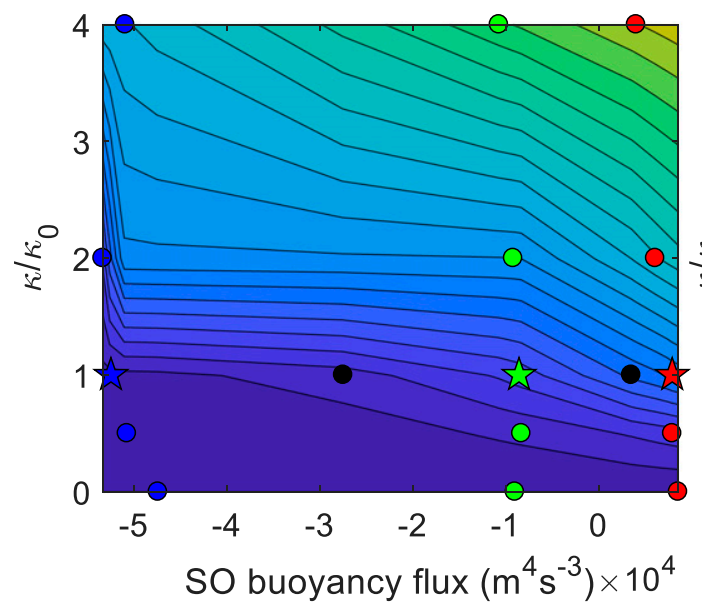

(b) Direct wind Pathway (NADW_wind)

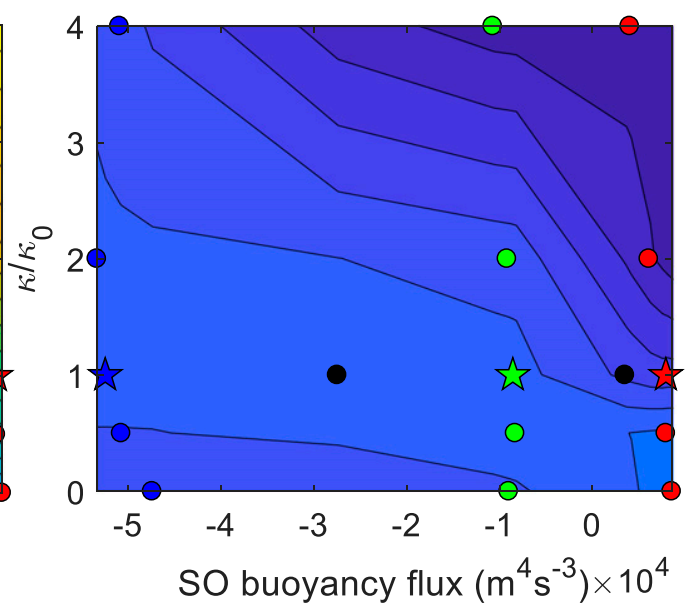

(d) Atlantic Pathway (NADW_At)

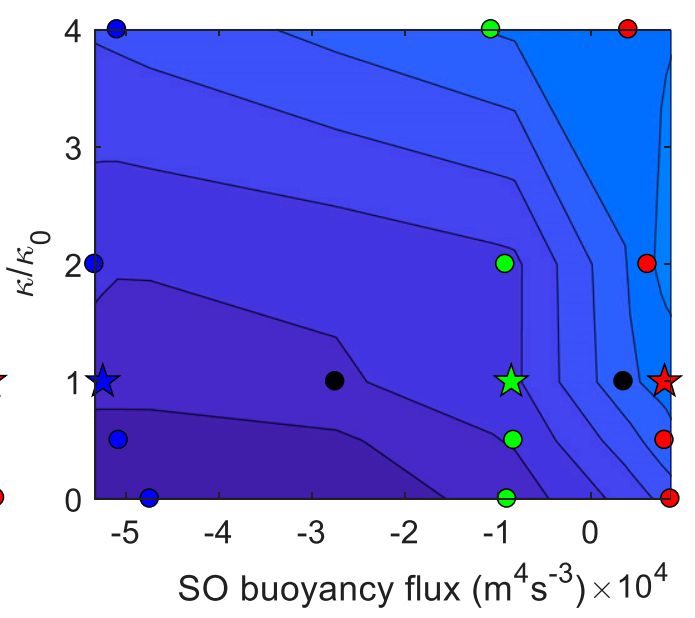

0

5

10

15

20

25

(Sv)

FIG. 7. As in Fig. 6, but showing overturning transport components as a function of Pacific vertical diffusivity $\kappa$ relative to the control value $\kappa_{0}$, and the area-integrated SO buoyancy flux.

Wind stress is fixed at its control value. As in the wind experiments, each of these diffusivity experiments are performed with varying sea ice freezing points and thus varying SO sea ice formation and buoyancy fluxes as described in section 2. The SO buoyancy flux is approximately constant in each buoyancy state as the Pacific diffusivity is perturbed (Fig. 7, colored symbols).

\section{a. Changes in the AMOC and overturning pathways}

The AMOC shoals (deepens) significantly with reduced (enhanced) Pacific diffusivity (Figs. 3, 4, and 5d,e) in all buoyancy states with a corresponding weakening (strengthening) of the AMOC (Fig. 7a). ${ }^{5}$ This is primarily due to changes in the Pacific basin circulation with the PDW cell weakening (strengthening) in all buoyancy states as the Pacific diffusivity is reduced (enhanced), as seen in middle panels of Figs. 3, 4, and 5d,e.

The Pacific pathway of NADW, NADW_Pac, is reduced to zero as the PDW cell is diminished (bottom of Fig. 7c) because

\footnotetext{
${ }^{5}$ Compare with Fig. 10d of Nadeau and Jansen (2020), which appears to have a similar AMOC sensitivity in diffusivitybuoyancy flux space despite the diffusivity being perturbed across the whole model domain.
} 
without Pacific basin upwelling there is no pathway to return this water to the upper cell of the Atlantic basin. The AMOC therefore shoals, reducing the cell overlap in the warm and present-day buoyancy states (Figs. 3d and 4d) to conserve volume, becoming akin to the cold state control (Fig. 5c) in structure. Although the Pacific pathway is greater in the warm state control, and thus the pathway decreases more as the Pacific diffusivity is reduced, the direct wind pathway increases in the warm state (red symbols at bottom of Fig. 7b). The increase in the direct wind pathway as the PDW cell weakens is because of the upwelling in the return pathway of PDW to the Atlantic (i.e., upwelling in PDW_At), is via the channels wind-driven upper cell in the warm state control (see section 6). The sensitivity of the AMOC to a reduced Pacific diffusivity in the present-day state is therefore similar to the warm state (Fig. 8b, green and red lines).

In the cold buoyancy state, though there is no pathway of NADW into the deep Pacific, reducing the Pacific diffusivity still weakens the AMOC because it reduces the direct wind pathway and the Atlantic pathway of NADW (blue symbols at the bottom of Figs. 7a,b,d) as the AMOC shoals (Fig. 5d).

The Pacific pathway of NADW increases in all buoyancy states as the Pacific diffusivity is enhanced (top of Fig. 7c) because the cell overlap increases and the PDW cell strengthens (Figs. 3e, 4e, and 5e). This leads to a significant strengthening of the AMOC, greatest in the present-day and warm buoyancy states (Fig. 8b, green and red lines), despite the direct wind pathway reducing to oppose this change (green and red symbols at top of Fig. 7b). The Atlantic pathway of NADW also increases in the present-day state as the AMOC deepens (green symbols at top of Fig. 7d).

\section{b. Summary and comparison of all experiments}

The sensitivity of the AMOC to varying Pacific diffusivity is highly dependent on the buoyancy forcing. It is more sensitive to a decrease in the diffusivity relative to the control value as the buoyancy forcing is varied from a cold toward a warm buoyancy state (bottom of Fig. 7a, and Fig. 8b). In contrast, as the diffusivity is increased relative to the control, the AMOC in the present-day buoyancy state is more sensitive than in the warm buoyancy state (top of Fig. 7a, and Fig. 8b) due primarily to a significant deepening of the AMOC, although the cold buoyancy state remains the least sensitive.

This contrasts with the SO wind experiments in which the cold buoyancy state is most sensitive to a reduction in wind stress, while the cold and present-day buoyancy states are equally sensitive to an enhanced wind stress (Figs. 6a and 8a).

\section{c. AMOC sensitivity to buoyancy forcing}

The sensitivity of the AMOC to changes in SO wind stress and Pacific diffusivity, varies with buoyancy forcing; thus its sensitivity to changes in buoyancy forcing, varies with wind stress and diffusivity. This can be inferred from Figs. 6a and 7a by comparing the changes in AMOC strength between buoyancy states (i.e., from left to right, between the blue and red symbols) as the wind stress or diffusivity changes. The AMOC is in general most sensitive to buoyancy forcing perturbations at low SO wind stress or at high Pacific diffusivity (orange lines in Figs. 8c,d, respectively). This is a consequence of the AMOC being more sensitive to SO wind stress under a cold climate buoyancy forcing (left side of Fig. 6a) and more sensitive to Pacific diffusivity toward a warm climate buoyancy forcing (right side of Fig. 7a). Since the AMOC is weaker in cooler climates, these sensitivity differences lead to a greater divergence in the strength of the AMOC between buoyancy states at a reduced SO wind stress or at an enhanced Pacific diffusivity.

While this dependence on buoyancy forcing is the case for changes from a cold to a warm buoyancy state (orange lines in Figs. $8 \mathrm{c}, \mathrm{d}$ ), changes to or from the present-day buoyancy state do not have this dependence in all cases (blue and red lines in Figs. 8c,d). The present-day state is as sensitive to enhanced wind stress as the cold state, and as or more sensitive to a change in diffusivity as in the warm state (see section $5 \mathrm{~b}$ ). Nonetheless, the sensitivity of the AMOC to a change from a present-day to a cold buoyancy forcing is significantly greater at enhanced Pacific diffusivity (Fig. 8d blue line), or at a SO wind stress lower than the control value (Fig. 8c, blue line) ${ }^{6}$

Our experiments only consider the equilibrium response of the AMOC to perturbations in buoyancy forcing, but models generally simulate a transient shoaling and weakening of the AMOC in response to a warmer climate (e.g., Weijer et al. 2020), the opposite to the equilibrium response. We suggest the dependence of the equilibrium response of the AMOC to changes from a present-day toward a cold buoyancy forcing, on the SO wind stress and Pacific diffusivity in our experiments, will be similar to the sensitivity of the transient response of the AMOC to a future warmer climate. This is due to the AMOC shoaling in both cases, albeit via different mechanisms ${ }^{7}$, and therefore changes in the pathways of NADW are likely to be analogous. This would imply the transient weakening of the AMOC in response to climate warming in a model would be greater at a low SO wind stress, or at a higher Pacific diffusivity. Further research is needed to determine if these sensitivity dependencies apply to the transient response of the AMOC.

\section{MOC upwelling mechanisms}

\section{a. Relation to $N A D W$ pathways}

We have separated the NADW pathways into the components that return water to the surface of the Atlantic basin (i.e., NADW_wind, NADW_Pac, and NADW_At). However, the relation between these components, and the wind- and diffusivedriven upwelling mechanisms is not always straightforward i.e.,

\footnotetext{
${ }^{6}$ The sensitivity to buoyancy forcing when the effects of SO winds and Pacific diffusivity on the buoyancy forcing are removed, by interpolation of the buoyancy forcing in the control experiments vertically in Figs. 6a and 7a, yield similar sensitivities (Fig. S2 in the online supplemental material).

${ }^{7}$ Jansen et al. (2018) use a single-basin model to show that warmer northern sourced waters lead to a transient shoaling of the AMOC in warmer climates, whereas in our experiments enhanced SO buoyancy fluxes in cooler climates lead to an equilibrium shoaling of the AMOC (see Ferrari et al. 2014; Jansen and Nadeau 2016).
} 


\section{AMOC sensitivity to wind, diffusivity and buoyancy forcing}

(a) Sensitivity to wind forcing

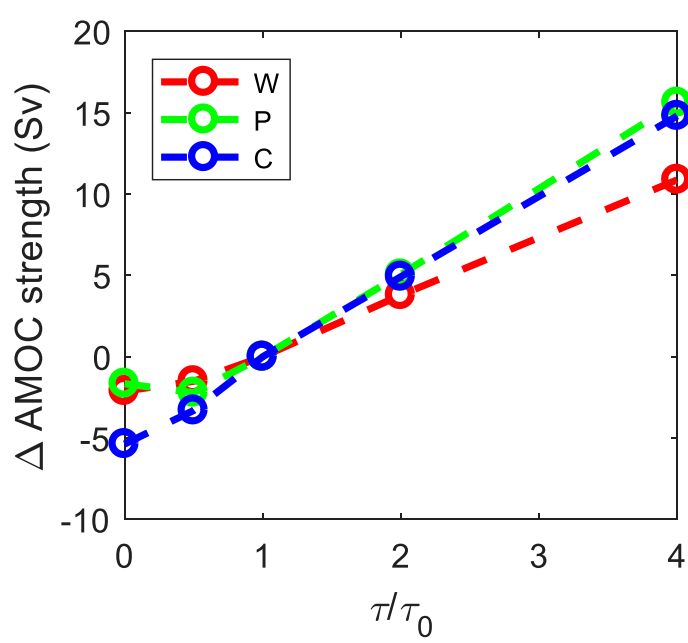

(b) Sensitivity to Pacific diffusivity

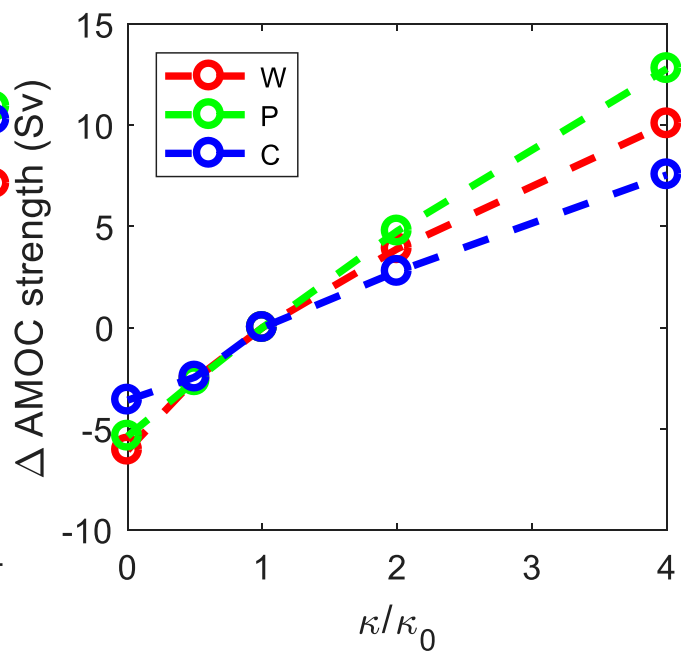

(c) Sensitivity to buoyancy forcing

(d) Sensitivity to buoyancy forcing
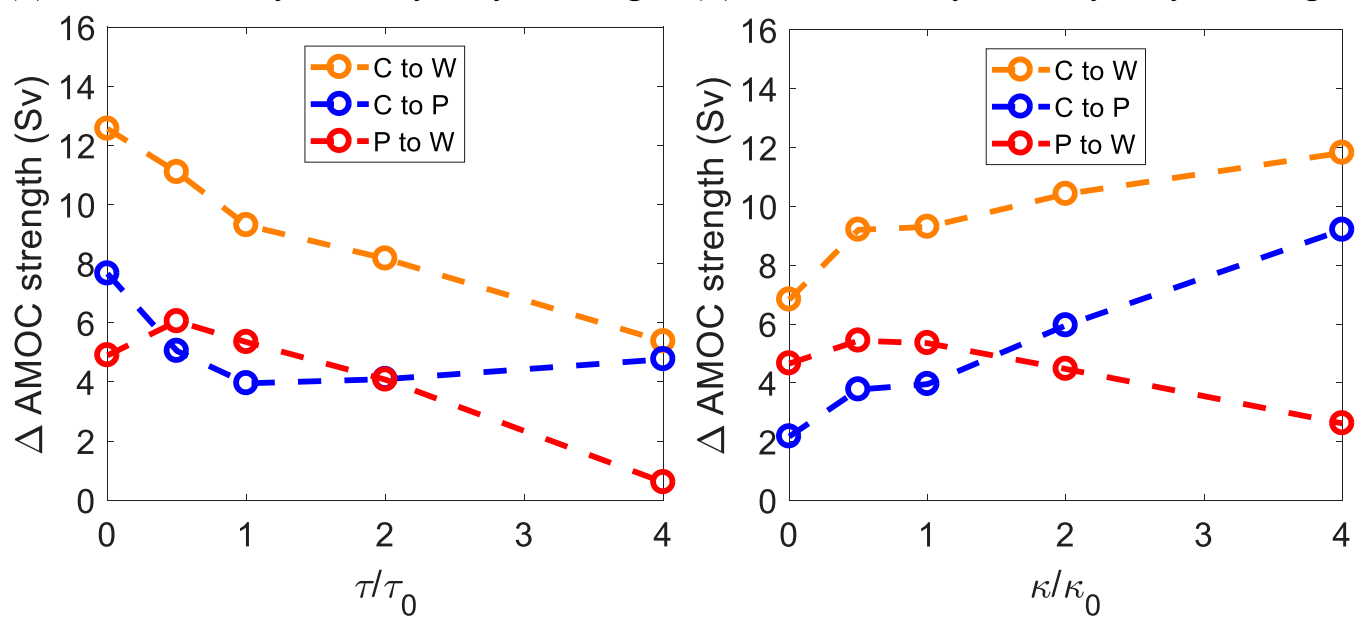

FIG. 8. Change in AMOC strength as a function of fractional change in (left) SO wind stress $\tau$ and (right) Pacific diffusivity $\kappa$ relative to the control values $\tau_{0}$ and $\kappa_{0}$, respectively, for (a),(b) warm (W), present day (P), and cold (C) buoyancy states where the change in AMOC strength is relative to the control values and for (c),(d) changes in buoyancy forcing between buoyancy states $\mathrm{C}$ and $\mathrm{W}$ (orange), $\mathrm{C}$ and $\mathrm{P}$ (blue), and $\mathrm{P}$ and $\mathrm{W}$ (red).

the Pacific pathway, NADW_Pac does not necessarily correspond to the component of the AMOC driven solely by Pacific diffusive upwelling. That said, the upwelling along the direct wind pathway, NADW_wind, and the Atlantic pathway, NADW_At are in fact essentially driven solely by the SO winds and Atlantic basin diffusion, respectively, since these pathways have a single upwelling mechanism (Fig. 2). NADW_wind is the pathway of NADW out of the Atlantic basin that is subsequently upwelled by the channels winddriven upper cell, before returning directly back into the Atlantic basin. NADW_At is the pathway of NADW upwelled diffusively in the Atlantic basin, before returning north nearer the surface, without flowing into the channel.
The upwelling mechanisms that drive the Pacific pathway of NADW, NADW_Pac, are less easily identified. Upwelling along this pathway in the control (and all nonzero perturbation) experiments is initially via the channel's anticlockwise lower cell, which may be partially wind induced. Waters then flow into the Pacific basin at depth, and in the warm state control, some of the Pacific diffusively upwelled waters are later upwelled by the channel's wind-driven upper cell, before returning to the Atlantic via zonal flows.

The calculated pathways of NADW in our present-day control experiment do approximately equal the drivers of the AMOC (i.e., wind driven, and Atlantic and Pacific diffusively driven for the NADW_wind, NADW_At, and NADW_Pac 
pathways, respectively) although there is some deviation in the warm buoyancy state as we shall now discuss.

\section{b. Implications}

The separation of NADW flowing into the channel's lower cell and ultimately into the Pacific basin (NADW_Pac), from that flowing into the channel's upper cell and directly back into the Atlantic along the direct wind pathway (NADW_wind), is an important distinction. If the two were not separated, SO wind-driven upwelling could be assumed to drive the AMOC in its entirety (bar the diffusive upwelling in the Atlantic) with only a minor role played by Pacific diffusive upwelling. However, our experiments show that without diffusive upwelling in the Pacific basin, the Pacific pathway of NADW, NADW_Pac, is not present and thus the AMOC weakens despite no change in SO wind-driven upwelling (symbols at bottom of Figs. 7a,c). The channel's eddy-induced lower cell is then isolated from the NADW cell (i.e., no cell overlap) to satisfy continuity (Figs. 3d, 4d, and 5d), due to the AMOC shoaling.

However, as the Pacific diffusivity is reduced in the warm buoyancy state, the direct wind pathway increases even though the wind is held constant, opposing some of the reduction in the Pacific pathway (red symbols at bottom of Fig. 7b). This is due to a component of the Pacific pathway being both wind and diffusively driven in the control warm state, because about $3 \mathrm{~Sv}$ of the PDW returning to the Atlantic is first upwelled via the channel's wind-driven upper cell. In contrast, in the present-day state control, the Pacific pathway is entirely diffusively driven, i.e., the direct wind pathway is equal to the total adiabatic upwelling by the channel's wind-driven upper cell.

The wind has a significant impact on the channel circulation structure and thus, one might suppose, would be essential to maintain the Pacific pathway, since without the wind-induced tilting of isopycnals, the channel's eddy-induced lower cell might not be generated. However, in the zero wind experiments performed here, the Pacific pathway is in fact maintained (and even slightly enhanced) at zero wind (bottom of Fig. 6c). In any case, the Pacific pathway in the present-day state control is a driver of the AMOC via diffusive Pacific upwelling. The nonlinearity of the response means that the strength of the AMOC is not simply the addition of the wind driving with zero Pacific diffusivity and the diffusive driving with zero winds.

In the present-day state control, our overturning pathway calculations suggest about $5.4 \mathrm{~Sv}(47 \%)$ of the AMOC is driven by the SO winds, about $3.4 \mathrm{~Sv}(29 \%)$ is driven by Pacific diffusive upwelling, and about $2.8 \mathrm{~Sv}(24 \%)$ is driven by Atlantic upwelling. Of course, the AMOC also depends on the North Atlantic surface boundary conditions enabling NADW to form, and the relative importance of the wind and diffusive upwelling will depend on the model geometry (Nadeau and Jansen 2020). In summary, the sensitivity of the AMOC to reduced wind or Pacific diffusivity is generally not equal to these respective upwelling mechanisms due to changes in the MOC structure leading to opposing increases in other pathways, moderating the change in AMOC strength.

\section{Conclusions}

In this two-part study, the dependence of the strength and pathways of the MOC on Southern Ocean buoyancy and wind forcing, and on Pacific vertical diffusivity, has been investigated using a two-basin model with a southern circumpolar channel. In this paper (Part II) we have focused on wind and diffusive effects.

The AMOC strength depends on the wind stress over the SO and the vertical diffusivity in the Pacific, and increases as either of these increase. However, that dependence varies with the SO buoyancy forcing, represented here by the low-ice warm, the present-day and the cold states, each with varying SO sea ice formation rates. Specifically, we find the following:

1) AMOC strengthens (weakens) with enhanced (reduced) SO wind stress or Pacific diffusivity under all buoyancy forcing states, being dominated by changes in the direct wind and Pacific pathways of NADW, respectively, but the sensitivity varies as follows:

(i) Sensitivity to wind is greatest in the cold state, and least sensitive in the warm and present-day states.

(ii) Sensitivity to diffusivity is greatest in the warm state, similar to that in the present-day state, and least in the cold state.

2) AMOC is consequently more sensitive to buoyancy forcing at a low $S O$ wind stress or at high Pacific diffusivity because of the AMOC being weaker in cooler states.

These sensitivity differences between the warm and cold buoyancy states in response to changed wind and diffusivity arise because the direct wind pathway (i.e., NADW upwelling in the SO and returning directly to the Atlantic) increases at the expense of the Pacific pathway as the buoyancy forcing is perturbed toward a cold glacial state (Fig. 10 in Part I illustrates these pathways; also see Nadeau and Jansen 2020). When the two basins are largely decoupled (in the cold states), Pacific diffusivity has little effect on the AMOC and SO wind effects are dominant. In warm climates, the Pacific diffusivity can play a much larger role.

The changes leading to these MOC variations and AMOC sensitivity differences are summarized below:

- The AMOC is generally deeper in the warm and present-day states than in the cold state, and the connection between the Atlantic and Pacific is greater.

- An increased Pacific diffusivity deepens the AMOC at the channel-basin boundary, altering the overlap between the upper NADW cell and the (global-integrated) lower cell. Similarly, a reduced diffusivity shoals the AMOC. This is in agreement with Nadeau and Jansen (2020).

- SO wind perturbations significantly alter the SO circulation and thus the depth of the global-integrated cell interface at the channel-basin boundary, both directly, and indirectly by varying SO isopycnal tilt and sea ice export.

- Structural changes in the MOC with diffusivity and wind perturbations can lead to compensating changes in the direct wind and Pacific pathways, respectively, in the warm and present-day states in some cases, reducing the sensitivity of the AMOC. 
These results have several ramifications for the cause and nature of changes in the structure of the ocean in glacial times. In particular, they suggest that although a reduction of SO zonal wind forcing leads to a small weakening of the present-day AMOC due to a reduced direct wind pathway, it does not of itself shoal the AMOC because the Pacific pathway can be maintained, broadly consistent with the results of Jochum and Eden (2015). However, if the buoyancy forcing is that of a cold state, changes in wind can have a great effect, more like changes in wind in a single-basin configuration.

Although the response of the MOC to diffusivity, wind, and buoyancy forcing seems complex, the underlying causes are clear. In climates similar or warmer than that of today, the AMOC is deep and there is a substantial pathway into the Pacific. Diffusive upwelling in the Pacific modulates the strength of the AMOC and thus there is substantial sensitivity to its diffusivity. In colder climates, the upper and lower overturning cells are at leading-order independent of each other and the influence of the Pacific on the Atlantic is small. The AMOC is then primarily sensitive to the SO wind forcing, whereas sensitivity to Pacific diffusivity is small.

The exact sensitivities we have found in this study depend, of course, on the nature of our model, and it would be helpful to perform similar simulations using models with more realistic geometries and higher resolution. Global eddy resolving simulations with realistic geometry are unfortunately currently out of reach because of the length of time of the simulations. Nevertheless, we believe the qualitative results will hold, as the ocean pathways underlying the AMOC response in our model are not dependent on details of the geometry. The impact of varying the shape of the vertical diffusivity profile and latitude of the SO winds on the sensitivity is another avenue of research. The dependence of the sensitivity of the AMOC to buoyancy forcing on the SO wind stress and Pacific diffusivity, and to wind stress (and diffusivity) on the buoyancy forcing revealed in this study may explain some of the divergence in the response of the AMOC to past and future climate forcing in GCM's, since they all operate with different sets of parameters.

We conclude by summarizing how our results affect the interpretation of the overturning circulation in today's climate and a cooler, glacial, past climate. In today's climate, both Southern Ocean wind effects and diffusive upwelling, mainly in the Pacific, play a role in driving the ocean's overturning circulation. In cooler climates, the overturning circulation in the Atlantic and Pacific may become more decoupled, and if so it is Southern Ocean wind effects that predominantly drive the overturning state, and the AMOC is weaker and shallower than of today.

Acknowledgments. We greatly appreciate and thank Jonathan Lauderdale for his advice on using the MITgcm, and we thank Tobia Tudino for his help in using the University supercomputer. Many thanks are given to two anonymous reviewers for their insightful comments, which have improved this paper. We all acknowledge NERC Grants NE/P021298/1: Southern Ocean Optimal Approach To Assess the Carbon State, Variability and Climatic Drivers (SONATA) and NE/T00942X/1: Dynamics of
Warm Past and Future Climates. Authors Baker and Watson thank the Royal Society for funding via a Research Professorship held by Watson (RP140106).

\section{REFERENCES}

Baker, J. A., A. J. Watson, and G. K. Vallis, 2020: Meridional overturning circulation in a multibasin model Part I: Dependence on Southern Ocean buoyancy forcing. J. Phys. Oceanogr., 50, 1159-1178, https://doi.org/10.1175/JPO-D19-0135.1.

Bishop, S. P., P. R. Gent, F. O. Bryan, A. F. Thompson, M. C. Long, and R. Abernathey, 2016: Southern Ocean overturning compensation in an eddy-resolving climate simulation. J. Phys. Oceanogr., 46, 1575-1592, https://doi.org/10.1175/JPO-D-150177.1.

Bryan, K., and L. J. Lewis, 1979: A water mass model of the world ocean. J. Geophys. Res., 84, 2503-2517, https://doi.org/10.1029/ JC084iC05p02503.

Cessi, P., 2019: The global overturning circulation. Annu. Rev. Mar. Sci., 11, 249-270, https://doi.org/10.1146/annurevmarine-010318-095241.

Curry, W., and D. Oppo, 2005: Glacial water mass geometry and the distribution of $\delta^{13} \mathrm{C}$ of $\sum \mathrm{CO}_{2}$ in the Western Atlantic Ocean. Paleoceanography, 20, PA1017, https://doi.org/10.1029/ 2004PA001021.

Doos, K., and A. Coward, 1997: The Southern Ocean as the major upwelling zone of North Atlantic deep water. International WOCE Newsletter, No. 27, WOCE International Project Office, Southampton, United Kingdom, 3-4.

Farneti, R., T. L. Delworth, A. J. Rosati, S. M. Griffies, and F. Zeng, 2010: The role of mesoscale eddies in the rectification of the Southern Ocean response to climate change. J. Phys. Oceanogr., 40, 1539-1557, https://doi.org/10.1175/ 2010JPO4353.1.

Ferrari, R., M. F. Jansen, J. F. Adkins, A. Burke, A. L. Stewart, and A. F. Thompson, 2014: Antarctic sea ice control on ocean circulation in present and glacial climates. Proc. Natl. Acad. Sci. USA, 111, 8753-8758, https://doi.org/10.1073/ pnas.1323922111.

—, L. P. Nadeau, D. P. Marshall, L. C. Allison, and H. L. Johnson, 2017: A model of the ocean overturning circulation with two closed basins and a reentrant channel. J. Phys. Oceanogr., 47, 2887-2906, https://doi.org/10.1175/JPO-D-160223.1.

Gent, P. R., and J. C. McWilliams, 1990: Isopycnal mixing in ocean circulation models. J. Phys. Oceanogr., 20, 150-155, https://doi.org/10.1175/1520-0485(1990)020<0150:IMIOCM> 2.0.CO;2.

—_, J. Willebrand, T. J. McDougall, and J. C. McWilliams, 1995: Parameterizing eddy-induced tracer transports in ocean circulation models. J. Phys. Oceanogr., 25, 463-474, https://doi.org/10.1175/1520-0485(1995)025<0463:PEITTI> 2.0.CO;2.

Gnanadesikan, A., 1999: A simple predictive model for the structure of the oceanic pycnocline. Science, 283, 2077-2079, https://doi.org/10.1126/science.283.5410.2077.

Gregg, M. C., 1989: Scaling turbulent dissipation in the thermocline. J. Geophys. Res., 94, 9686-9698, https://doi.org/10.1029/ JC094iC07p09686.

Griffies, S. M., R. C. Pacanowski, and R. W. Hallberg, 2000: Spurious diapycnal mixing associated with advection in a $z$-coordinate ocean model. Mon. Wea. Rev., 128, 538-564, 
https://doi.org/10.1175/1520-0493(2000)128<0538:SDMAWA $>$ 2.0.CO;2.

Hibler, W. D., III, 1979: A dynamic thermodynamic sea ice model. J. Phys. Oceanogr., 9, 815-846, https://doi.org/10.1175/15200485(1979)009<0815:ADTSIM > 2.0.CO;2.

Jansen, M. F., and L. P. Nadeau, 2016: The effect of Southern Ocean surface buoyancy loss on the deep-ocean circulation and stratification. J. Phys. Oceanogr., 46, 3455-3470, https:// doi.org/10.1175/JPO-D-16-0084.1.

,$- \ldots$, and T. M. Merlis, 2018: Transient versus equilibrium response of the ocean's overturning circulation to warming. J. Climate, 31, 5147-5163, https://doi.org/10.1175/JCLI-D-170797.1.

Jochum, M., and C. Eden, 2015: The connection between Southern Ocean winds, the Atlantic meridional overturning circulation, and Indo-Pacific upwelling. J. Climate, 28, 9250-9257, https:// doi.org/10.1175/JCLI-D-15-0263.1.

Jones, C. S., and P. Cessi, 2016: Interbasin transport of the meridional overturning circulation. J. Phys. Oceanogr., 46, 1157-1169, https://doi.org/10.1175/JPO-D-15-0197.1.

Kohfeld, K. E., R. M. Graham, A. M. De Boer, L. Sime, E. W. Wolff, C. Le Quéré, and L. Bopp, 2013: Southern Hemisphere westerly wind changes during the Last Glacial Maximum: Paleo-data synthesis. Quat. Sci. Rev., 68, 76-95, https://doi.org/ 10.1016/j.quascirev.2013.01.017.

Kuhlbrodt, T., A. Griesel, M. Montoya, A. Levermann, M. Hofmann, and S. Rahmstorf, 2007: On the driving processes of the Atlantic meridional overturning circulation. Rev. Geophys., 45, RG2001, https://doi.org/10.1029/2004RG000166.

Lauderdale, J. M., A. C. N. Garabato, K. I. C. Oliver, M. J. Follows, and R. G. Williams, 2013: Wind-driven changes in Southern Ocean residual circulation, ocean carbon reservoirs and atmospheric $\mathrm{CO}_{2}$. Climate Dyn., 41, 2145-2164, https://doi.org/ 10.1007/s00382-012-1650-3.

Ledwell, J. R., A. J. Watson, and C. S. Law, 1993: Evidence for slow mixing across the pycnocline from an open-ocean tracer release experiment. Nature, 364, 701-703, https://doi.org/10.1038/ $364701 \mathrm{a} 0$.

Losch, M., D. Menemenlis, J.-M. Campin, P. Heimbach, and C. Hill, 2010: On the formulation of sea-ice models. Part 1: Effects of different solver implementations and parameterizations. Ocean Modell., 33, 129-144, https://doi.org/10.1016/ j.ocemod.2009.12.008.

Lumpkin, R., and K. Speer, 2007: Global ocean meridional overturning. J. Phys. Oceanogr., 37, 2550-2562, https://doi.org/ 10.1175/JPO3130.1.

Lynch-Stieglitz, J., W. B. Curry, and N. Slowey, 1999: Weaker Gulf Stream in the Florida Straits during the last glacial maximum. Nature, 402, 644-648, https://doi.org/10.1038/45204.

Marshall, J., A. Adcroft, C. Hill, L. Perelman, and C. Heisey, 1997a: A finite-volume, incompressible Navier Stokes model for studies of the ocean on parallel computers. J. Geophys. Res., 102, 5753-5766, https://doi.org/10.1029/ 96JC02775.

— C. Hill, L. Perelman, and A. Adcroft, 1997b: Hydrostatic, quasihydrostatic, and nonhydrostatic ocean modelling. J. Geophys. Res., 102, 5733-5752, https://doi.org/10.1029/96JC02776.

Muglia, J., and A. Schmittner, 2015: Glacial Atlantic overturning increased by wind stress in climate models. Geophys. Res. Lett., 42, 9862-9868, https://doi.org/10.1002/2015GL064583.

Munday, D., H. Johnson, and D. Marshall, 2013: Eddy saturation of equilibrated circumpolar currents. J. Phys. Oceanogr., 43, 507532, https://doi.org/10.1175/JPO-D-12-095.1.
Munk, W., 1966: Abyssal recipes. Deep-Sea Res., 13, 707-730, https://doi.org/10.1016/0011-7471(66)90602-4.

Nadeau, L.-P., and M. F. Jansen, 2020: Overturning circulation pathways in a two-basin ocean model. J. Phys. Oceanogr., 50, 2105-2122, https://doi.org/10.1175/JPO-D-20-0034.1.

_, R. Ferrari, and M. F. Jansen, 2019: Antarctic sea ice control on the depth of North Atlantic deep water. J. Climate, 32, 2537-2551, https://doi.org/10.1175/JCLI-D-18-0519.1.

Newsom, E. R., and A. F. Thompson, 2018: Reassessing the role of the Indo-Pacific in the ocean's global overturning circulation. Geophys. Res. Lett., 45, 12 422-12 431, https://doi.org/10.1029/ 2018GL080350.

Nikurashin, M., and G. Vallis, 2011: A theory of deep stratification and overturning circulation in the ocean. J. Phys. Oceanogr., 41, 485-502, https://doi.org/10.1175/2010JPO4529.1.

- and - 2012: A theory of the interhemispheric meridional overturning circulation and associated stratification. J. Phys. Oceanogr., 42, 1652-1667, https://doi.org/10.1175/JPO-D-110189.1.

Otto-Bliesner, B. L., C. D. Hewitt, T. M. Marchitto, E. Brady, A. Abe-Ouchi, M. Crucifix, S. Murakami, and S. L. Weber, 2007: Last glacial maximum ocean thermohaline circulation: PMIP2 model intercomparisons and data constraints. Geophys. Res. Lett., 34, L12706, https://doi.org/10.1029/2007GL029475.

Redi, M. H., 1982: Oceanic isopycnal mixing by coordinate rotation. J. Phys. Oceanogr., 12, 1154-1158, https://doi.org/10.1175/15200485(1982)012<1154:OIMBCR > 2.0.CO;2.

Rojas, M., and Coauthors, 2009: The southern westerlies during the Last Glacial Maximum in PMIP2 simulations. Climate Dyn., 32, 525-548, https://doi.org/10.1007/s00382-008-0421-7.

Samelson, R. M., 2004: Simple mechanistic models of middepth meridional overturning. J. Phys. Oceanogr., 34, 2096-2103, https:// doi.org/10.1175/1520-0485(2004)034<20:SMMOMM>2.0.CO;2.

Sun, S., I. Eisenman, L. Zanna, and A. L. Stewart, 2020: Surface constraints on the depth of the Atlantic Meridional overturning circulation: Southern ocean versus North Atlantic. J. Climate, 33, 3125-3149, https://doi.org/10.1175/JCLI-D-19-0546.1.

Talley, L. D., 2013: Closure of the global overturning circulation through the Indian, Pacific, and Southern oceans: Schematics and transports. Oceanography, 26, 80-97, https://doi.org/10.5670/ oceanog.2013.07.

Thompson, A. F., A. Stewart, and T. Bischoff, 2016: A multibasin residual-mean model for the global overturning circulation. J. Phys. Oceanogr., 46, 2583-2604, https://doi.org/10.1175/ JPO-D-15-0204.1.

Toggweiler, J. R., and B. Samuels, 1995: Effect of Drake Passage on the global thermohaline circulation. Deep-Sea Res., 42, 477-500, https://doi.org/10.1016/0967-0637(95)00012-U.

$\longrightarrow$, and - 1998: On the ocean's large-scale circulation near the limit of no vertical mixing. J. Phys. Oceanogr., 28, 1832-1852, https://doi.org/10.1175/1520-0485(1998)028<1832:OTOSLS> 2.0.CO;2.

_, J. L. Russell, and S. R. Carson, 2006: Midlatitude westerlies, atmospheric $\mathrm{CO}_{2}$, and climate change during the ice ages. Paleoceanography, 21, PA2005, https://doi.org/10.1029/ 2005 PA001154.

Toole, J. M., K. L. Polzin, and R. W. Schmitt, 1994: Estimates of diapycnal mixing in the abyssal ocean. Science, 264, 11201123, https://doi.org/10.1126/science.264.5162.1120.

Vallis, G. K., 2000: Large-scale circulation and production of stratification: Effects of wind, geometry, and diffusion. J. Phys. Oceanogr., 30, 933-954, https://doi.org/10.1175/ 1520-0485(2000)030<0933:LSCAPO > 2.0.CO;2. 
_ 2017. Atmospheric and Oceanic Fluid Dynamics: Fundamentals and Large-Scale Circulation. Cambridge University Press, 2nd ed., 946 pp.

Wang, W., and R. X. Huang, 2005: An experimental study on thermal circulation driven by horizontal differential heating. J. Fluid Mech., 540, 49-73, https://doi.org/10.1017/ S002211200500577X.

Watson, A. J., and A. C. Naveria Garabato, 2006: The role of Southern Ocean mixing and upwelling in glacial-interglacial atmospheric $\mathrm{CO}_{2}$ change. Tellus, $\mathbf{5 8 B}, 73-87$, https://doi.org/ 10.1111/j.1600-0889.2005.00167.x.
Weijer, W., W. Cheng, O. A. Garuba, A. Hu, and B. T. Nadiga, 2020: CMIP6 models predict significant 21st century decline of the Atlantic meridional overturning circulation. Geophys. Res. Lett., 47, e2019GL086075, https://doi.org/10.1029/2019GL086075.

Wolfe, C. L., and P. Cessi, 2010: What sets the strength of the middepth stratification and overturning circulation in eddying ocean models? J. Phys. Oceanogr., 40, 1520-1538, https:// doi.org/10.1175/2010JPO4393.1.

Zhang, J., and W. D. Hibler III, 1997: On an efficient numerical method for modeling sea ice dynamics. J. Geophys. Res., 102, 8691-8702, https://doi.org/10.1029/96JC03744. 